Article

\title{
Incorporation of Lipids into Wheat Bran Cellulose/Wheat Gluten Composite Film Improves Its Water Resistance Properties
}

\author{
Guanghui Shen ${ }^{1}$, Guoxian $\mathrm{Yu}^{1}$, Hejun $\mathrm{Wu}^{1}{ }^{1}$, Shanshan $\mathrm{Li}^{1}{ }^{1}$, Xiaoyan Hou ${ }^{2}$, Meiliang Li ${ }^{1}$, Qingye Li ${ }^{1}$, \\ Xingyan Liu ${ }^{1}$, Man Zhou ${ }^{1}$, Anjun Chen ${ }^{1}$ and Zhiqing Zhang ${ }^{1, *}$ \\ 1 College of Food Science, Sichuan Agricultural University, Ya'an 625014, China; 13994@sicau.edu.cn (G.S.); \\ ddj112001@163.com (G.Y.); hejunwu520@163.com (H.W.); lss@sicau.edu.cn (S.L.); liml@sicau.edu.cn (M.L.); \\ qingyeli@sicau.edu.cn (Q.L.); 1xy05@126.com (X.L.); zhouman@sicau.edu.cn (M.Z.); \\ anjunc003@163.com (A.C.) \\ 2 Institute of Food Processing and Safety, Sichuan Agricultural University, Ya'an 625014, China; \\ houxiaoyan106@163.com \\ * Correspondence: zqzhang721@163.com
}

check for updates

Citation: Shen, G.; Yu, G.; Wu, H.; Li, S.; Hou, X.; Li, M.; Li, Q.; Liu, X.; Zhou, M.; Chen, A.; et al. Incorporation of Lipids into Wheat Bran Cellulose/Wheat Gluten Composite Film Improves Its Water Resistance Properties. Membranes 2022, 12, 18. https://doi.org/ 10.3390/membranes12010018 Academic Editor: Ismael Marcet

Received: 26 November 2021 Accepted: 20 December 2021 Published: 24 December 2021

Publisher's Note: MDPI stays neutral with regard to jurisdictional claims in published maps and institutional affiliations.

Copyright: (C) 2021 by the authors. Licensee MDPI, Basel, Switzerland. This article is an open access article distributed under the terms and conditions of the Creative Commons Attribution (CC BY) license (https:// creativecommons.org/licenses/by/ $4.0 /)$.

\begin{abstract}
This work evaluated the improvement effects of lipids incorporation on water resistance of composite biodegradable film prepared with wheat bran cellulose/wheat gluten (WBC/WG) using an alkaline-ethanol film forming system. Four types of lipids, paraffin wax (PW), beeswax (BW), paraffin oil (PO), and oleic acid (OA), were tested. We found that PW, BW, and PO incorporation at 5-20\% improved water vapor permeability $(W V P)$ and surface hydrophobicity of prepared films. Particularly, incorporation of $15 \% \mathrm{BW}$ could best improve the water resistance properties of the film, with the lowest $W V P$ of $0.76 \times 10^{-12} \mathrm{~g} / \mathrm{cm} \cdot \mathrm{s} \cdot \mathrm{Pa}$ and largest water contact angle $(W C A)$ of $86.18^{\circ}$. Incorporation of OA led to the decline in moisture barrier properties. SEM images revealed that different lipids incorporation changed the morphology and of the composite film, and cross-sectional morphology indicated BW-incorporated film obtained more uniform and compact structures compared to other films. Moreover, Fourier transform infrared spectra indicated that the incorporation of PW or BW enhanced the molecular interactions between the film components, confirmed by the chemical shift of characteristic peaks at 3277 and $1026 \mathrm{~cm}^{-1}$. Differential scanning calorimetry results revealed that incorporation of PW, BW, and PO increased films' melting point, decomposition temperatures, and enthalpy values. Furthermore, the presence of most lipids decreased tensile strength and elongation at the break of the film. Overall, the composite film containing 15\% BW obtained the most promising water resistance performance and acceptable mechanical properties, and it thus most suitable as a hydrophobic biodegradable material for food packaging.
\end{abstract}

Keywords: hydrophobic composite film; wheat gluten; lipids; beeswax; water barrier properties

\section{Introduction}

Food packaging is essential for protecting the quality and safety of food products during their storage and distribution. Plastic films are widely used as food packaging materials due to their properties including light weight and water resistance, as well as their low cost. However, most of these plastic films are hardly degradable, and can thus cause serious environmental pollution. Further, some harmful contaminants in the films can migrate into food, which can in turn increase potential risks of foods [1]. Currently, there are growing interests on the development of eco-friendly films with desirable performances that can be applied to produce food packaging materials [2].

Natural polymers, including polysaccharides and proteins, are the best candidates for producing food packaging materials. Not only can these polymers be easily extracted from agricultural by-products, but they also have many advantages, one of which is their degradability in the environment [3]. Wheat gluten (WG) is a by-product from wheat starch 
manufacturing process; it possesses excellent film-forming and gas barrier properties [4]. WG-based films have good heat-sealing properties and good oxygen and oil resistance properties [5]. However, the WG-based films have poor mechanical and water barrier properties, which have greatly restricted their applications [6]. High contents of water and oxygen inside the food package are the primary factors that can affect quality and shelf-life of food as moisture can change the food quality, increasing chemical reaction and microbial spoilage [7]. Therefore, the mechanical and water barrier properties of WG films ought to be improved to expand their applications.

As a natural polysaccharide polymer with good thermal stability, plant cellulose has been used as a natural reinforcer in food packaging films [8]. Numerous recent studies have shown that incorporating plant-derived celluloses into protein- or starch-based films could improve their mechanical properties $[9,10]$. These binary-blend matrixes offer the potential to combine different desirable material properties from two individual polymers, to produce optimized films for food packing application. In view of the good film forming and oxygen barrier properties of WG and the excellent mechanical reinforcing effect of wheat bran cellulose (WBC), we developed an alkaline-ethanol film forming system to improve the compatibility of WBC with WG protein, in which we found that the addition of $40 \%$ $(\mathrm{m} / \mathrm{m}) \mathrm{WBC}$ could enhance tensile property of WBC/WG binary-blend film, with tensile strength (TS) increased from 8.65 to $20.44 \mathrm{MPa}$ [11]. Despite this finding on complementary advantages of WBC and WG, the water barrier properties of resultant binary-blend film were not significantly improved due to the hydrophilic nature of WBC component [12].

Currently, several approaches have been conducted to improve water barrier properties of protein-based films, such as chemical modifications including physical, chemical, and enzymatic treatment [13], and incorporation of hydrophobic agents such as plant essential oils, animal fats, mineral oil, and other lipid materials $[6,14,15]$. Waxes are generally composed of fatty acids and fatty alcohols. As hydrophobic molecules, some waxes or their compounds have been incorporated (as additives) to improve water barrier properties and to modify hydrophobic properties of protein-based films. These additives exhibited diverse roles in different composite films. One report has shown that candelilla wax can significantly reduce water vapor permeability (WVP) of pea protein isolate-based film, while oleic acid (OA) reduced the water barrier properties and had a plasticizing effect on the film, making it more elastic [14]. Paraffin wax (PW), which is mainly composed of long-chain saturated fatty acids straight-chain hydrocarbons including C16:0 and C18:1, has been shown to best improve water resistance properties of fish gelatin films [16]. Beeswax (BW), a nature wax produced by honeybees has been shown to enhance that of protein-based films but reduce their mechanical properties [17]. BW (10-15\%) have also been shown to improve water vapor barriers of gelatin-wax films, but not their mechanical properties [18]. Paraffin oil, also named liquid paraffin, can control the viscosity and stability of emulsion, and exhibited reinforcement effect on the structure compactness and water barrier property of CMC coating [19].

Although previous works have demonstrated the enhancing effects of various types of lipids on water barrier resistance of bio-based film, these published reports focused mainly on the improvement of barrier properties of films by adding lipids (as surfactants) into a pure polysaccharide- or protein-derived emulsion. In fact, the improvement effect of various types of lipids addition on moisture resistance of binary blend film based on plant cellulose and proteins are not well understood. This work thus aimed to investigate the role of lipids in improving the properties, particularly for water resistance properties of WBC/WG binary blend film. In this study, four types of lipids including PW, BW, PO, and $\mathrm{OA}$ were incorporated into WBC/WG alkaline-ethanol film forming dispersions to cast various lipid-incorporated ternary blend films. The morphology, thermal stability, and water resistance and mechanical properties of the films were subsequently characterized. 


\section{Materials and Methods}

\subsection{Materials}

WG ( $\geq 75 \%$ protein) was obtained from Fengqiu Huafeng Powder Industry Co., Ltd. (Xinxiang, Henan, China). Wheat bran was purchased from a local market (Ya'an, Sichuan, China). PW (melting temperature range: $53-55^{\circ} \mathrm{C}$ ) was supplied by Shanghai Hua Shen Rehabilitation Equipment Co., Ltd. (Shanghai, China). BW (melting temperature range: $60-65^{\circ} \mathrm{C}$ ) was obtained from Tianjin Kaitong Reagent Co., Ltd. (Tianjin, China). PO and OA (analytical pure) were purchased from Chengdu Cologne Reagent Co., Ltd. (Chengdu, Sichuan, China).

\subsection{Preparation of Wheat Bran Cellulose}

Wheat bran cellulose was prepared according to a previously reported method [20]. Briefly, WB was ground using a high-speed grinder; after that, it was washed, dried at $60{ }^{\circ} \mathrm{C}$, and then filtered through an 80-mesh sieve to obtain cellulose powder. The powder was dispersed in distilled water at a ratio of 1:10 $(w / v)$, and the resultant dispersion was then boiled for $10 \mathrm{~min}$. After its $\mathrm{pH}$ was adjusted to approximately 13.0 with $2 \mathrm{~mol} / \mathrm{L} \mathrm{NaOH}$, the dispersion was heated at $80{ }^{\circ} \mathrm{C}$ for $4 \mathrm{~h}$. The sample was subsequently centrifuged at $8000 \times g$ for $10 \mathrm{~min}$, and the precipitate was washed with distilled water until its $\mathrm{pH}$ reached a neutral $\mathrm{pH}$. Afterward, the $\mathrm{pH}$ value was adjusted to $\mathrm{pH} 1.5$ using $2 \mathrm{~mol} / \mathrm{L} \mathrm{HCl}$, and incubated at $60^{\circ} \mathrm{C}$ for $2 \mathrm{~h}$ in a water bath. The obtained precipitate was filtered and washed with deionized water until its $\mathrm{pH}$ became neutral; thereafter, it was dried at $55{ }^{\circ} \mathrm{C}$ for $8 \mathrm{~h}$. The dried sample was ground using a superfine grinder and then passed through a 120-mesh sieve to obtain WBC.

\subsection{Preparation of Film-Forming Dispersions}

The film-forming dispersion for WBC/WG films was prepared using an alkaline film-forming system reported in our previous study [11]. In brief, the WG dispersion was prepared by suspending $25.6 \mathrm{~g} \mathrm{WG}$ in $154 \mathrm{~mL}$ of $35 \%$ ethanol solution at $45^{\circ} \mathrm{C}$, and the $\mathrm{pH}$ was then adjusted to 11.5 using $2.0 \mathrm{~mol} / \mathrm{L} \mathrm{NaOH}$. Afterward, WG dispersion was heated at $80^{\circ} \mathrm{C}$ for 15 min to break disulfide bonds in protein (to denature protein). The WBC dispersion was prepared by dispersing $14.4 \mathrm{~g}$ of WBC in $160 \mathrm{~mL}$ of deionized water using a high-pressure homogenizer, and was then poured into the prepared WG dispersion. After that, $8.00 \mathrm{~g}$ glycerol (as plasticizer) and $0.06 \mathrm{~g}$ xanthan gum (as a stabilizer) were mixed at $45^{\circ} \mathrm{C}$ and were then added into the WBC/WG dispersion and mixed vigorously. Subsequently, $86 \mathrm{~mL}$ of absolute ethanol was added into the above dispersion to a final concentration of $35 \%$ under vigorous stirring. The dispersion $\mathrm{pH}$ was adjusted to 11.5 and then subjected to a high-pressure homogenizer at $25 \mathrm{MPa}$ for $10 \mathrm{~min}$.

An emulsifier containing monoacylglycerides and Tween-80 at a mass ratio of 2:3 was first melted at $70{ }^{\circ} \mathrm{C}$ in a water bath. The melted emulsifier (10\%) was then mixed with different concentrations of lipids (5\%,10\%, 15\%, and 20\% (w/w), dry film basis) to generate transparent lipid solutions, which were further melted at the same temperature. The melted lipid solutions were subsequently mixed with the prepared WBC/WG filmforming dispersion by homogenizing at $13,000 \mathrm{r} / \mathrm{min}$ for $15 \mathrm{~min}$ at $70{ }^{\circ} \mathrm{C}$ (to allow lipids to remain in the liquid state) using a homogenizer (FJ200-SH, Shanghai Specimen Model Factory, Shanghai, China). The obtained film-forming dispersions were eventually vacuumdegassed at $-0.09 \mathrm{MPa}$ for $30 \mathrm{~min}$.

\subsection{Preparation of Films}

All films were casted from the above prepared degassed film-forming dispersions in leveled PMMA (polymethyl methacrylate)-coated plates (dimensions: $15 \times 15 \mathrm{~cm}$ ) at $55^{\circ} \mathrm{C}$ for $5 \mathrm{~h}$. The films were dried at $25^{\circ} \mathrm{C}$ in a desiccator at $51 \pm 1 \%$ relative humidity (RH) for $48 \mathrm{~h}$ [9], and then peeled off and subjected to following characterization in Section 2.5. The WBC/WG films without lipids addition were used as the control. 


\subsection{Characterization of Films}

\subsubsection{Scanning Electron Microscopy (SEM)}

The prepared films were cut into $10 \times 10 \mathrm{~mm}^{2}$ squares and dried in a desiccator containing silica gel for 2 weeks. After that, the surface and cross-sectional morphology of the films were observed under a scanning electron microscope (Ultra 55, Carl Zeiss AG, Oberkochen, Germany).

\subsubsection{Fourier Transform Infrared (FT-IR) Spectroscopy}

FT-IR spectra of the films were recorded on a Nicolet IS10 FT-IR spectrometer (Thermo Fisher Scientific, Waltham, MA, USA) equipped with a Smart iTR diamond attenuated total reflectance (ATR) accessory. The spectra data was scanned from 4000 to $650 \mathrm{~cm}^{-1}$ at a resolution of $4 \mathrm{~cm}^{-1}$ for 32 scans per film.

\subsubsection{Differential Scanning Calorimetry (DSC)}

DSC curves were recorded using a differential scanning calorimeter (Q200M, TA Instruments, New Castle, DE, USA). The films (approximately $5 \mathrm{mg}$ ) were sealed in an aluminum pan and then heated from 25 to $350^{\circ} \mathrm{C}$ at a rate of $10^{\circ} \mathrm{C} / \mathrm{min}$. An empty pan was used as a blank control.

\subsubsection{Determination of Water Solubility}

Dried films (dimensions: $20 \times 20 \mathrm{~mm}$, dried at $105^{\circ} \mathrm{C}$, weight: $W 1$ ) were shaken in $25 \mathrm{~mL}$ of distilled water at $25^{\circ} \mathrm{C}$ for $24 \mathrm{~h}$. Afterward, the films were removed from water and then dried to a constant weight at $105^{\circ} \mathrm{C}$. The dried films were weighted to obtain $W 2$. Water solubility (WS) was calculated from $W 1$ and $W 2$ by the following equation:

$$
W S(\%)=\frac{W 1-W 2}{W 2} \times 100
$$

\subsubsection{Water Vapor Permeability (WVP)}

Water vapor permeability $(W V P, \mathrm{~g} / \mathrm{cm} \cdot \mathrm{s} \cdot \mathrm{Pa})$ of the films was determined using a modified ASTM E96-04 gravimetric method [21]. The prepared films $(20 \times 20 \mathrm{~mm})$ were sealed in Payne permeability cups containing anhydrous calcium chloride at $25^{\circ} \mathrm{C}$ and $81 \% \mathrm{RH}$ for $7 \mathrm{~d}$, during which they were weighed every $24 \mathrm{~h}$ using an analytical balance $( \pm 0.0001 \mathrm{~g})$. Water vapor transmission rate $(W V T R)$ and $W V P$ were calculated according to the following equations:

$$
W V T R=\frac{\Delta m}{A \times T}
$$

where $\Delta m$ is the weight gain $(\mathrm{g}), A$ is the exposed area of the film $\left(\mathrm{cm}^{2}\right)$, and $T$ is the time interval (s).

$$
W V P=\frac{W V T R \times d}{\Delta P}
$$

where $d$ is the measured film thickness $(\mathrm{cm})$ and $\Delta P$ is the water vapor pressure across the film (Pa).

Film thickness was measured at five random positions by a digital micrometer (Zhongtian Experimental Instrument Co., Ltd., Zhengzhou, China) at an accuracy of $1.0 \mu \mathrm{m}$.

\subsubsection{Water Contact Angle (WCA)}

WCA values on both sides of film were measured using a video-based contact angle measuring device (OCA-H200, Dataphysics Co., Ltd., Filderstadt, Germany). One microliter of distilled water was deposited onto surface of the film (dimensions: $30 \times 30 \mathrm{~mm}$ ), and the droplet images were recorded and used to estimate the WCA values. Each measurement was carried out three replicates at random positions on the surface of film. 


\subsubsection{Mechanical Properties}

Tensile strength (TS, MPa) and elongation at break $(E A B, \%)$ of the film were determined at $25 \pm 1{ }^{\circ} \mathrm{C}$ using a texture analyzer (TA. XT Plus, Stable Micro Systems, London, UK) according to previously published method [22] with minor modifications. The film samples (dimensions: $50 \times 10 \mathrm{~mm}$ ) were fixed on the probe. The cross-head speed was set at $1 \mathrm{~mm} / \mathrm{s}$, and the initial distance was set at $30 \mathrm{~mm}$. TS and $E A B$ values were calculated from the stress-strain curves. The test environment was maintained at $51 \pm 1 \% \mathrm{RH}$. Six replicates of each sample were performed, and the data were averaged.

\subsection{Statistical Analysis}

All data were expressed as means \pm SDs. One-way analysis of variance (ANOVA) and Duncan's multiple range test were performed using SPSS 27.0 (SPSS, Chicago, IL, USA) at a significant level of $p=0.05$. Data fitting was carried out on OriginPro 9.1 (OriginLab Corp., Northampton, MA, USA).

\section{Results and Discussion}

\subsection{Film Morphology}

Figure 1 shows the morphology of native WBC film, the air-side surface, and the crosssection of WBC/WG film containing $15 \%$ lipids. The native WBC had a long block-like shape (Figure 1A). The surface of WBC/WG film was inhomogeneous containing a few particles (Figure 1B) of the unincorporated WBC or WBC/WG aggregates. By contrast, the cross-section of the WBC/WG film exhibited a fish scale-like shape and a compact network and was pore free (Figure 1C).

The morphology of lipid-incorporated composite films depended on types of lipids. As illustrated in Figure 1D, numerous lipid aggregate was observed on the air-side surface of PW-incorporated film. Additionally, the cross-section of PW-incorporated films was inhomogeneous, and the structure close to the surface of PMMA side was denser, as can be observed in Figure 1E. The aggregated particles distributed in the top half of the cross-section close to the air-side likely were lipid globules. The roughness of the airside surface of the PW-incorporated film may be caused by phase separation during the drying process of films and resulted in lipids aggregated at the air-film interface. Smaller aggregated particles on the air-side surface of BW-incorporated film were also observed (Figure 1F). The cross-sectional morphology of BW-incorporated film indicated uniform and compact structures with a few micropores inside the film, and BW particles were tightly embedded in the film (Figure 1G). These observed morphology characteristics suggested that the incorporated BW was uniformly distributed as micro lipid droplets dispersed in the composite film emulsion. Such a phenomenon has been observed in gelatin-beeswax films previously reported by Zhang et al. [18].

On the contrary, incorporation of PO or OA showed slightly effects on morphology of the WBC/WG film. Despite of the obviously particles on the surface of PO-incorporated film (Figure 1H) compared with the control (Figure 1B), its cross-section possessed more ordered structures (Figure 1I). In addition, PO and other components in the cross-section of PO-incorporated film were hardly distinguishable. The cross-sectional morphology of OA-incorporated film, however, showed that the film contained numerous small air bubbles (Figure $1 \mathrm{~K}$ ), which may be generated due to incomplete defoaming during the preparation of film dispersions. It is worth mentioning that when incorporating OA into WBC/WG dispersion, a large amount of air bubbles formed, and only a small amount of which were defoamed. These bubbles may try to escape into air during film drying, in turn causing circular holes with basin shape on the surface of OA-incorporated film (Figure 1J). In the presence of $\mathrm{NaOH}$ in film dispersions, OA could convert into sodium oleate, which possesses excellent foaming properties [23] and subsequently contributed to air bubbles. Altogether, we inferred that morphology of the film varies with the physical state and chemical composition of the lipids incorporated. 


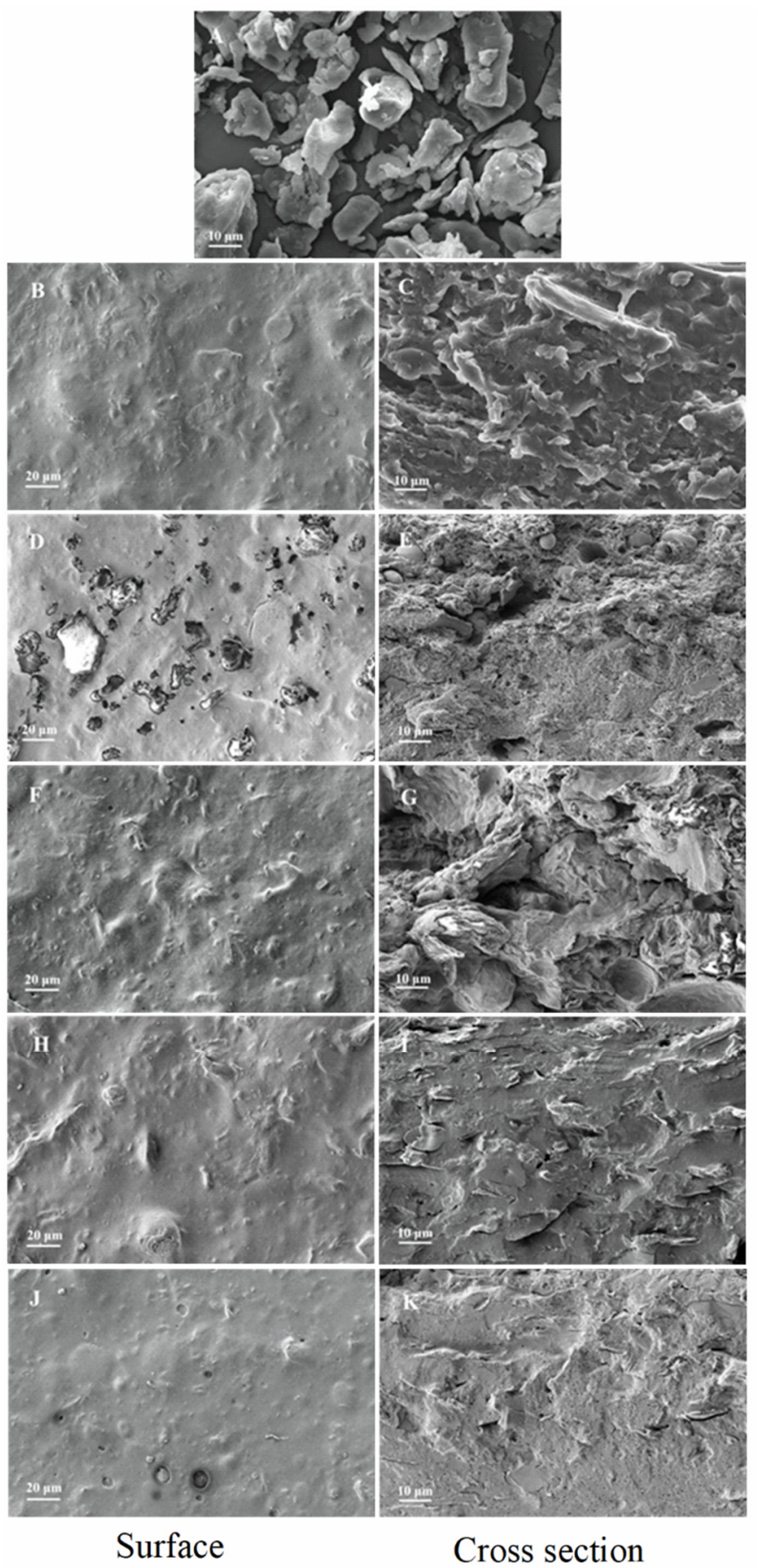

Figure 1. SEM images of wheat bran cellulose (WBC) ( $\times 1000$ magnification), surface morphology $(\times 500$ magnification $)$ and cross section morphology $(\times 1000$ magnification $)$ of WBC/WG composite films. WBC (A); WBC/WG films (B,C); paraffin wax-incorporated WBC/WG films (D,E); beeswaxincorporated WBC/WG films (F,G); paraffin oil-incorporated WBC/WG films (H,I); and oleic acidincorporated WBC/WG films $(\mathbf{J}, \mathbf{K})$.

\subsection{FT-IR Spectra}

As presented in Figure 2, FT-IR spectra of the WBC/WG film exhibited the characteristic bands as follows: $3500-3200 \mathrm{~cm}^{-1}$ (-OH stretching vibrations), $2800-3000 \mathrm{~cm}^{-1}$ (C-H stretching vibrations), $1200-1800 \mathrm{~cm}^{-1}$ (carboxylic groups region stretching vibrations), and around $1020-1030 \mathrm{~cm}^{-1}$ (C-O stretching vibrations) $[24,25]$. These bands were slightly changed after the lipids' incorporation, and their changes were dependent on types of the used lipids. Compared with WBC/WG film, the band at $3277 \mathrm{~cm}^{-1}$ of PO- and 
OA-incorporated films was slightly blue-shifted (to a higher wavenumber) to $3280 \mathrm{~cm}^{-1}$, which indicates that incorporation of the liquid lipids (PO and OA) can weaken hydrogen bonding interaction between matrix components [25]. By contrast, incorporation of the two solid lipids (waxes) caused a slight red-shift (to lower wavenumber), indicating the interaction between the components was stronger [26]. Sharp peaks at 2916 and $2848 \mathrm{~cm}^{-1}$ due to the asymmetric and symmetric stretching vibrations of aliphatic $\mathrm{C}-\mathrm{H}$ groups in fatty acid chains, which are the characteristic peaks of most lipids [16], were not observed in the lipid-free WBC/WG film, but were observed in the WBC/WG film containing two solid lipids. Furthermore, a band at $1538 \mathrm{~cm}^{-1}$, which is the characteristic band of $\mathrm{N}-\mathrm{H}$ deformation [27], was shifted to a higher wavenumber upon the incorporation of $\mathrm{PO}$ or OA. Additionally, the characteristic band at $1026 \mathrm{~cm}^{-1}$ was shifted to $1030 \mathrm{~cm}^{-1}$ upon the incorporation of solid lipids, but was shifted to a lower wavenumber of $1023 \mathrm{~cm}^{-1}$ when liquid lipids were incorporated into the films. These shifts demonstrate the incorporation of lipids can change the molecular interaction in the composite films. This is in line with a previous report by Zhang et al. [25], which has described that the addition of hydrophobic agents can cause distinct changes to the molecular interaction and in turn causes the characteristic peaks to shift.

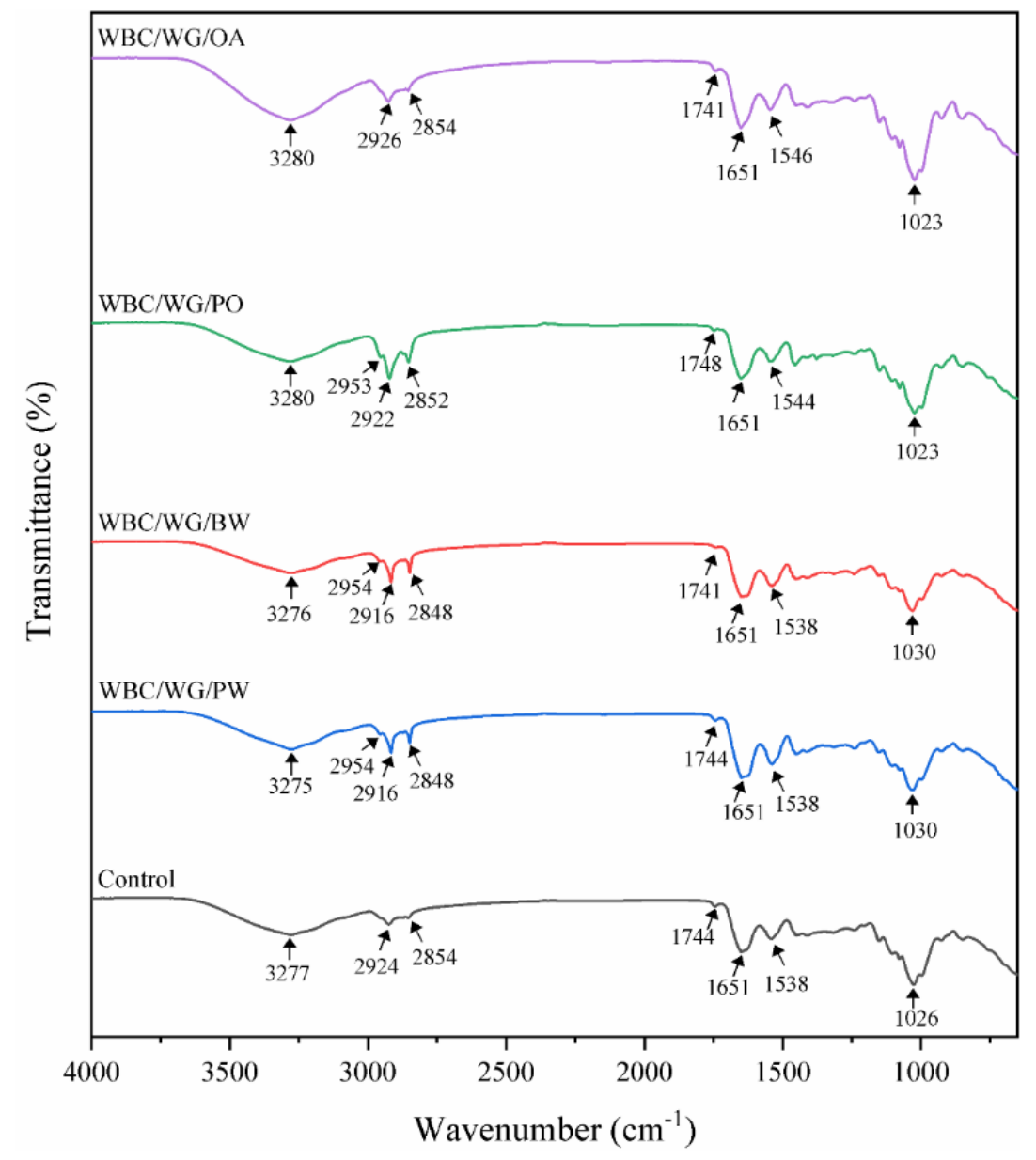

Figure 2. FTIR spectra of composite WBC/WG film incorporated with four types of lipids. WBC/WG: wheat bran cellulose/wheat bran composite film; WBC/WG/PW: paraffin wax-incorporated WBC/WG film; WBC/WG/BW: beeswax-incorporated WBC/WG film; WBC/WG/PO: paraffin oil-incorporated WBC/WG film; WBC/WG/OA: oleic acid-incorporated WBC/WG film.

\subsection{Thermal Properties of Film}

The differential scanning calorimetry was particularly used to evaluate the changes in phase transitions of bio-based polymer films during the thermal processing $[28,29]$. The 
DSC curves, melting temperature, and enthalpy values of all films are illustrated in Figure 3. The WBC/WG film exhibited two endothermic peaks at 140.13 and $273.48^{\circ} \mathrm{C}$, which may be associated with the combined melting and thermal decomposition of WBC/WG film matrix. The films containing solid lipids exhibited two endothermic peaks at the temperature range of 30-70 ${ }^{\circ} \mathrm{C}$, which are the melting temperature of the solid lipids [25]. The two endothermic peaks of WBC/WG film were shifted to higher temperatures at 141.38 and $275.62{ }^{\circ} \mathrm{C}$ in PW-incorporated film, indicating PW enhanced the thermal stability of the WBC/WG film. On the other hand, the incorporation of BW caused the melting peak at $140.13{ }^{\circ} \mathrm{C}$ to shift to a lower temperature at $135.97^{\circ} \mathrm{C}$. It appears that BW, which has a higher melting point than other lipids, may not be homogeneously dispersed in the films during film drying, thereby causing obvious phase transition and separation [25]. The incorporation of PO did not cause the change of the melting temperature, but could increase the decomposition temperature, which indicates PO can enhance the thermal stability of WBC/WG film. Incorporation of OA greatly decreased the temperatures of the two endothermic peaks, causing the film to have a lower thermal stability.

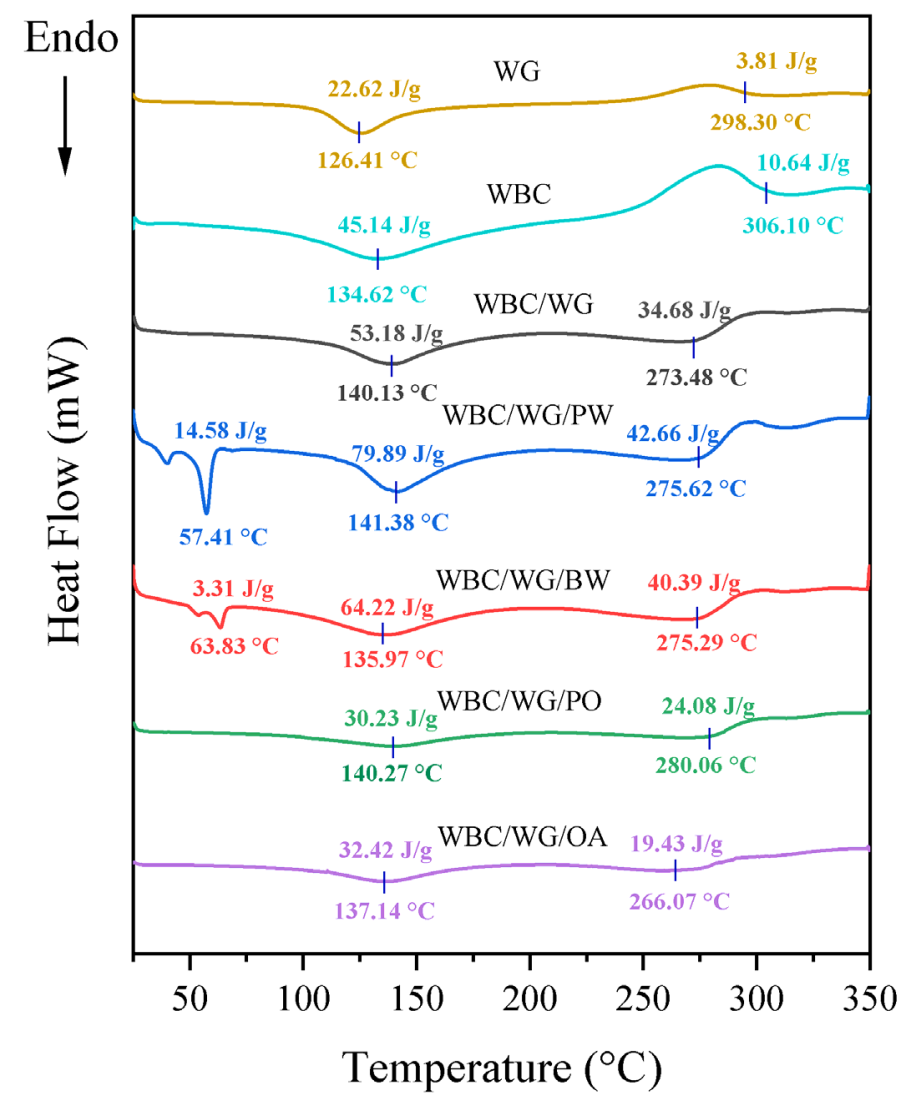

Figure 3. DSC curves of wheat bran (WG), wheat bran cellulose (WBC) and WBC/WG composite films incorporated with four types of lipids. WBC/WG: wheat bran cellulose/wheat bran composite film; WBC/WG/PW: paraffin wax-incorporated WBC/WG film; WBC/WG/BW: beeswax-incorporated WBC/WG film; WBC/WG/PO: paraffin oil-incorporated WBC/WG film; WBC/WG/OA: oleic acid-incorporated WBC/WG film.

In addition to the DSC curves, enthalpy values $(\Delta H)$ are another indicator that can indicate the molecular interactions in the amorphous phase and the crystalline structure of the films [30]. As shown in Figure 3, the incorporation of PW, BW, or PO caused the increase of the enthalpy values of the composite films, indicating that these lipids can slightly increase the thermal stability of the films. This is due to that the incorporation of lipids allows strong and compact network structure to be formed [25]. Specifically, the incorporation of lipids (PW, BW, or PO) enhanced the molecular interactions between WBC 
and WG in the composite film, in turn increasing its thermal stability. By contrast, a large decrease of the enthalpy values of the OA-incorporated film was observed, indicating that the incorporation of OA could decrease the thermal stability of the films. These results indicate that only PW, BW, and PO can improve the thermal stability of WBC/WG films, likely due to the intrinsic physicochemical properties of these lipids [25].

\subsection{Water-Resistance Properties}

\subsubsection{Water Solubility}

The mechanical characteristics of packaging films are determined by its use [29]. It is believed that lower water solubility (WS) of a film is desirable when applied to preserve lower moisture content food inside the food package during storage. As shown in Table 1, the incorporation of lipids decreased WS values of the films. A similar observation caused by the incorporation of waxes has also been reported [18,31]. Comparing all lipids, OA could best reduce the WS values of the film. This is most likely due to that OA could distributed more uniformly in film-forming emulsion as compared to other used lipids, and could thus more effectively minimize the contact area between the film and water molecules.

Table 1. Effect of incorporation of lipids on water solubility (WS), water vapor permeability (WVP) and water contact angle (WCA) of WBC/WG composite films.

\begin{tabular}{|c|c|c|c|c|c|}
\hline \multirow{2}{*}{$\begin{array}{l}\text { Lipid } \\
\text { Type }\end{array}$} & \multirow{2}{*}{$\begin{array}{c}\text { Lipid } \\
\text { Concentration }(\%)\end{array}$} & \multirow{2}{*}{ WS (\%) } & \multirow{2}{*}{$\begin{array}{c}\text { WVP } \\
\left(10^{-12} \mathrm{~g} / \mathrm{cm} \cdot \mathrm{s} \cdot \mathrm{Pa}\right)\end{array}$} & \multicolumn{2}{|c|}{$W C A\left({ }^{\circ}\right)$} \\
\hline & & & & Air-Side & PMMA-Side \\
\hline Control & 0 & $22.59 \pm 0.26^{a}$ & $1.63 \pm 0.01^{a}$ & $55.78 \pm 3.27^{\mathrm{e}}$ & $73.89 \pm 3.00^{\mathrm{e}}$ \\
\hline \multirow{4}{*}{ PW } & 5 & $21.64 \pm 0.18^{b}$ & $1.14 \pm 0.08^{\mathrm{def}}$ & $68.86 \pm 3.56^{\mathrm{cd}}$ & $73.60 \pm 2.79 \mathrm{e}$ \\
\hline & 10 & $21.06 \pm 0.36^{\mathrm{bcd}}$ & $1.02 \pm 0.03 \mathrm{gh}$ & $56.60 \pm 4.83^{\mathrm{e}}$ & $74.28 \pm 2.92^{\mathrm{e}}$ \\
\hline & 15 & $19.91 \pm 0.45^{\text {ef }}$ & $0.78 \pm 0.06^{\mathrm{ij}}$ & $56.17 \pm 3.60^{\mathrm{e}}$ & $84.88 \pm 5.31^{b}$ \\
\hline & 20 & $18.88 \pm 0.52$ gh & $1.01 \pm 0.05^{\mathrm{h}}$ & $54.81 \pm 0.72^{\mathrm{e}}$ & $95.46 \pm 2.01^{a}$ \\
\hline \multirow{4}{*}{ BW } & 5 & $21.31 \pm 0.44^{\mathrm{bcd}}$ & $1.23 \pm 0.03^{\mathrm{cd}}$ & $73.70 \pm 4.06^{b c}$ & $75.34 \pm 2.87 \mathrm{de}$ \\
\hline & 10 & $20.80 \pm 0.32^{\mathrm{cd}}$ & $1.12 \pm 0.05^{\mathrm{ef}}$ & $67.50 \pm 2.91^{\mathrm{cd}}$ & $80.58 \pm 3.54^{\mathrm{bcd}}$ \\
\hline & 15 & $19.82 \pm 0.62^{\text {efg }}$ & $0.76 \pm 0.02^{j}$ & $66.68 \pm 2.46^{\mathrm{d}}$ & $86.18 \pm 1.20^{b}$ \\
\hline & 20 & $18.50 \pm 0.25^{\mathrm{h}}$ & $1.02 \pm 0.06^{\mathrm{gh}}$ & $57.96 \pm 0.65^{\mathrm{e}}$ & $85.62 \pm 2.53^{b}$ \\
\hline \multirow{4}{*}{$\mathrm{PO}$} & 5 & $21.54 \pm 0.34^{b c}$ & $1.39 \pm 0.04^{b}$ & $66.95 \pm 3.74^{d}$ & $75.02 \pm 0.55 \mathrm{de}$ \\
\hline & 10 & $20.46 \pm 0.48^{\text {def }}$ & $1.17 \pm 0.04 \mathrm{def}$ & $76.68 \pm 3.32^{b}$ & $77.72 \pm 1.60$ cde \\
\hline & 15 & $19.77 \pm 0.57^{\mathrm{efg}}$ & $0.85 \pm 0.03^{\mathrm{i}}$ & $91.21 \pm 3.50^{a}$ & $81.90 \pm 4.53^{b c}$ \\
\hline & 20 & $19.29 \pm 0.26^{g h}$ & $1.10 \pm 0.04^{\mathrm{fg}}$ & $86.30 \pm 4.94^{\mathrm{a}}$ & $84.84 \pm 3.31^{b}$ \\
\hline \multirow{4}{*}{$\mathrm{OA}$} & 5 & $20.76 \pm 0.39 b c$ & $1.28 \pm 0.05^{c}$ & $51.43 \pm 3.87$ ef & $64.87 \pm 1.09^{f}$ \\
\hline & 10 & $19.44 \pm 0.55^{\mathrm{fgh}}$ & $1.20 \pm 0.10^{\text {cde }}$ & $46.80 \pm 2.39 \mathrm{fg}$ & $63.99 \pm 0.89^{f}$ \\
\hline & 15 & $18.82 \pm 0.60 \mathrm{gh}$ & $1.09 \pm 0.02 \mathrm{fgh}$ & $41.04 \pm 1.44 \mathrm{~g}$ & $62.56 \pm 4.29^{f}$ \\
\hline & 20 & n.a. & n.a. & n.a. & n.a. \\
\hline
\end{tabular}

The values sharing different superscript letters in the same column were statistically different at $p<0.05$ by Duncan's multiple range test; n.a. not analyzed. Film incorporated $20 \%$ OA not evaluated because hardly peel off.

\subsubsection{Water Vapor Permeability (WVP)}

The higher water vapor permeability $(W V P)$ is the major drawback of biopolymers films, due to the hydrophilic nature of protein and cellulose matrix [32]. WVP values of all composite films are listed in Table 1 . The WVP values of films containing 15\% PW, BW, $\mathrm{PO}$, and OA were lowest with values of about $51.9 \%, 53.1 \%, 47.8 \%$, and $32.5 \%$, respectively, and were lower than that of the control $\left(1.63 \times 10^{-12} \mathrm{~g} / \mathrm{cm} \cdot \mathrm{s} \cdot \mathrm{Pa}\right)$. PW, BW, PO, and OA are hydrophobic lipids, and could thus effectively repel moisture and reduce hydrophilic interactions; thus, they could significantly decrease the WVP values of the WBC/WG composite films. PW has also been incorporated in LDPE/PW composite film and found to lower the WVP value of the film [33]. However, as compared with those of the composite films containing $15 \%$ lipids, the WVP values of the composite films containing $20 \%$ lipids were slightly higher. This may be due to that when a higher lipid concentration was used, emulsification may be inadequate, causing the structure of film matrix to be inhomogeneous or destructed (Figure 1). A similar finding has also been previously reported by Zhang 
et al. [25]. Considering water barrier properties of all films, the film containing PW or BW had significantly $(p<0.05)$ lower WVP values than that containing PO or OA. This suggests that solid lipids (PW and BW) could more effectively enhance the water barrier properties of the films than liquid lipids (PO and OA). The different effects of lipids on reducing the WVP of the composite films not only are associated with the natures of the lipids, such as physical state, arrangement of chemical bonds, and hydrophobicity, but also are influenced by their interactions with other film's components [25].

\subsubsection{Water Contact Angle (WCA)}

WCA values of all films are shown in Table 1 . The WCA values on both sides of most films were less than $90^{\circ}$, indicating that the films are hydrophilic. Furthermore, the $W C A$ values of the air-side surfaces were lower than those of the PMMA-side surfaces, due to the air-side surfaces being coarser than the PMMA-side surfaces. Moreover, the WCA value of the film containing PW, BW, or PO was higher than that of the control. With the increase of lipid concentration, the WCA value of the PMMA-side surface of the film containing PW or BW increased, whereas that of the air-side surface decreased, which may be due to the increase of roughness of the air-side surface in the presence of more lipid (Figure 1). These show that the contact angle and wetting behavior of solid surfaces are affected by surface roughness, inhomogeneity, and particle shape and size. Unlike those of hydrophobic materials, the WCA values of hydrophilic materials usually decrease with the increase of surface roughness [34]. The WCA value of the PMMA-side surface of the film containing $20 \% \mathrm{PW}$ increased up to $95.46^{\circ}$, indicating that this surface became more hydrophobic in the presence of $20 \%$ PW. In contrast, the WCA value of the air-side surface of this film was not significantly changed. The WCA values of both sides of the film containing PO increased with increasing lipid concentration. The incorporation of $20 \%$ PO caused the WCA value of the air-side and the PMMA-side surfaces of the film to increase to 86.30 and $84.84^{\circ}$, respectively, which were $54.71 \%$ and $14.82 \%$, respectively, higher than those of the control. These observations show that PW, BW, and PO, which are highly hydrophobic, can effectively block the interactions between hydrophilic groups and water molecules. The decreased WCA values of both sides of the PO-incorporated film indicated OA reduces the hydrophobicity of the film.

\subsection{Mechanical Properties}

The tensile strength $(T S)$ and elongation at break $(E A B)$ are critical mechanical parameter of food packing materials. Strong tensile strength and low elongation are significant to provide the good protection of foods during circulation and storage [29]. Figure 4 shows TS and $E A B$ values of the prepared films. According to Figure $4 \mathrm{~A}$, the incorporation of lipids of all types caused TS to significantly decrease from 22.6 MPa to between 9 and 17.33 MPa. The degree of decrease, however, varied with the types and concentrations of lipids. Specifically, among all lipids, the incorporation of OA resulted in the lowest TS; and within OA with different concentrations, $15 \%$ OA resulted in the lowest TS (value $=7.5$ ). Comparing all lipids at different concentrations, the higher the lipid concentration, the lower the TS value, which is in line with many previously reported studies $[16,18]$. These results can be explained by lipids having a non-polymeric nature that limits their cohesive film-forming capacity [15], which in turn causes the film to have heterogeneous structure [35].

Furthermore, as shown in Figure 4B, the incorporation of PW, BW, or PO caused the $E A B$ to significantly decrease. This decrease may be caused by solid particles that can cause the formation of rigid dispersed phase in the film, in turn leading to decreased flexibility of the film [36]. In contrast, the incorporation of $\mathrm{OA}$ increased the $E A B$ value, suggesting that OA has a strong plasticizing effect on the films, causing the network structure of the film to be discontinuous [37]. Similar results have also been previously observed [3,16]. 

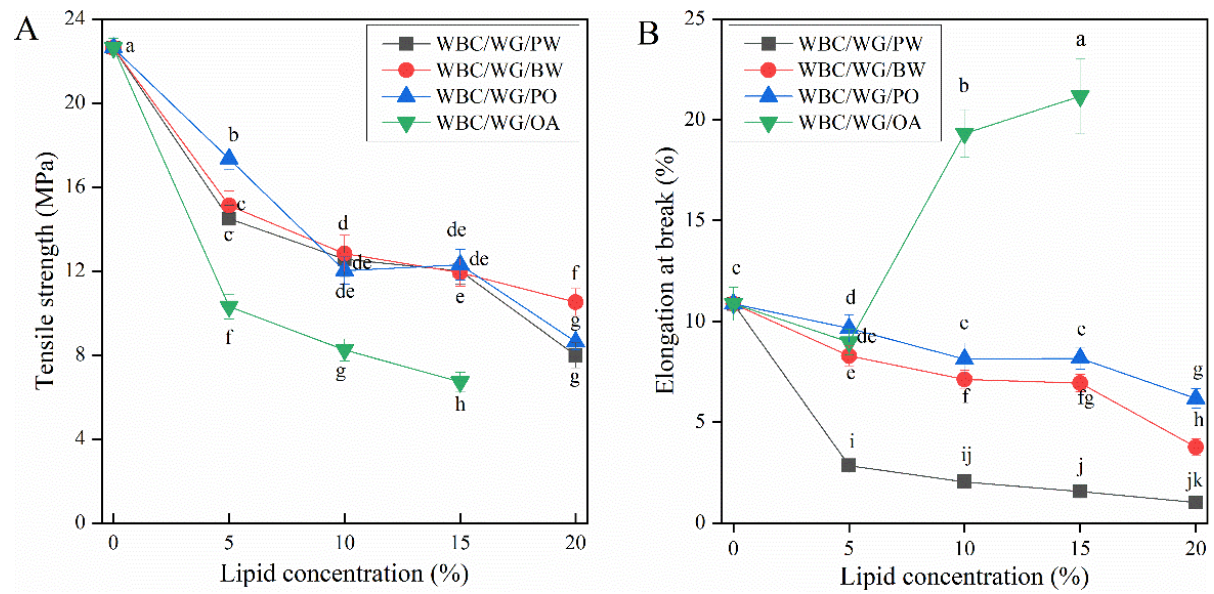

Figure 4. Tensile strength (A) and elongation at break (B) of WBC/WG composite films incorporated with four types of lipids. WBC/WG/PW: paraffin wax-incorporated WBC/WG film; WBC/WG/BW: beeswax-incorporated WBC/WG film; WBC/WG/PO: paraffin oil-incorporated WBC/WG film; WBC/WG/OA: oleic acid-incorporated WBC/WG film. The values sharing different superscript letters were statistically different at $p<0.05$.

\section{Conclusions}

In this paper, an alkaline-ethanol film forming system was successfully applied to develop hydrophobic WBC/WG blended films by incorporating four types of lipids. The effects of lipids addition on the water barrier properties and morphology of the blended films are dependent upon the physical state and chemical constituents of lipids. The incorporation of two solid lipids (PW and BW) showed more effectively improvement on water-resistance properties of WBC/WG films as compared to two liquid lipids (PO and $\mathrm{OA}$ ). However, $\mathrm{OA}$ incorporation decreased the mechanical properties of the films, as indicated by their lower TS and higher $E A B$ values. Moreover, the FTIR spectra revealed that the incorporation of PW and BW enhanced the molecular interaction between the film components, while the incorporation of $\mathrm{PO}$ and OA attenuated it. The DSC results indicated that the incorporation of lipids changed the inter-molecular interaction among the components of the films, thus their thermal properties. The incorporation of $15 \%$ BW could best improve the water resistance properties of WBC/WG film, lowering its $W V P$ value (to $0.76 \times 10^{-12} \mathrm{~g} / \mathrm{cm} \cdot \mathrm{s} \cdot \mathrm{Pa}$ ) and increase its $W C A$ (to $86.18^{\circ}$ on the PMMAside surface), and improve its mechanical properties. Collectively, the incorporation of BW could best improve the water resistance properties of WBC/WG hydrophobic films for food packaging. Further research should focus on developing BW/WBC/WG-based films with good antibacterial properties by adding natural antimicrobial substances into films dispersion, and further evaluation of potential fresh-keeping effects of films for food packaging is needed.

Author Contributions: Conceptualization, Z.Z.; data curation, X.L.; investigation, G.S. and G.Y.; methodology, H.W.; project administration, A.C. and Z.Z.; validation, S.L. and M.L.; visualization, X.H.; writing-original draft, G.S.; writing-review and editing, Q.L. and M.Z. All authors have read and agreed to the published version of the manuscript.

Funding: This research was funded by the Special Research Support Project from Sichuan Agricultural University, China (Project No. 03572107).

Institutional Review Board Statement: Not applicable.

Informed Consent Statement: Not applicable.

Data Availability Statement: Not applicable.

Conflicts of Interest: The authors declare no conflict of interest. 


\section{References}

1. Guerreiro, T.M.; de Oliveira, D.N.; Melo, C.; Lima, E.D.; Catharino, R.R. Migration from plastic packaging into meat. Food Res. Int. 2018, 109, 320-324. [CrossRef] [PubMed]

2. Deya, A.; Pandey, G.; Rawtania, D. Functionalized nanomaterials driven antimicrobial food packaging: A technological advancement in food science. Food Control 2022, 131, 108469. [CrossRef]

3. Burgos, N.; Valdes, A.; Jimenez, A. Valorization of agricultural wastes for the production of protein-based biopolymers. J. Renew. Mater. 2016, 4, 165-177. [CrossRef]

4. Delcour, J.A.; Joye, I.J.; Pareyt, B.; Wilderjans, E.; Brijs, K.; Lagrain, B. Wheat gluten functionality as a quality determinant in cereal-based food products. Annu. Rev. Food Sci. Technol. 2012, 3, 469-492. [CrossRef]

5. Hassan, B.; Chatha, S.A.S.; Hussain, A.I.; Zia, K.M.; Akhtar, N. Recent advances on polysaccharides, lipids and protein based edible films and coatings: A review. Int. J. Biol. Macromol. 2018, 109, 1095-1107. [CrossRef]

6. Rocca-Smith, J.R.; Marcuzzo, E.; Karbowiak, T.; Centa, J.; Giacometti, M.; Scapin, F.; Venir, E.; Sensidoni, A.; Debeaufort, F. Effect of lipid incorporation on functional properties of wheat gluten based edible films. J. Cereal Sci. 2016, 69, 275-282. [CrossRef]

7. Labuza, T.P.; Hyman, C.R. Moisture migration and control in multi-domain foods. Trends Food Sci. Technol. 1998, 9, 47-55. [CrossRef]

8. Cazon, P.; Vazquez, M.; Velazquez, G. Composite films of regenerate cellulose with chitosan and polyvinyl alcohol: Evaluation of water adsorption, mechanical and optical properties. Int. J. Biol. Macromol. 2018, 117, 235-246. [CrossRef]

9. Mastromatteo, M.; Chillo, S.; Buonocore, G.G.; Massaro, A.; Conte, A.; Del Nobile, M.A. Effects of spelt and wheat bran on the performances of wheat gluten films. J. Food Eng. 2008, 88, 202-212. [CrossRef]

10. Nataraj, D.; Sakkara, S.; Meenakshi, H.N.; Reddy, N. Properties and applications of citric acid crosslinked banana fibre-wheat gluten films. Ind. Crop. Prod. 2018, 124, 265-272. [CrossRef]

11. Yu, G.; Xiao, L.; Wu, H.; Li, S.; Luo, Q.; Liu, X.; Chen, A.; Shen, G.; Zhang, Z. Influence of alkaline-ethanol filming system for wheat gluten-based films containing wheat-bran cellulose. Food Mach. 2018, 34, 12-18.

12. Li, W.; Wang, S.; Wang, W.; Qin, C.; Wu, M. Facile preparation of reactive hydrophobic cellulose nanofibril film for reducing water vapor permeability (WVP) in packaging applications. Cellulose 2019, 26, 3271-3284. [CrossRef]

13. Wihodo, M.; Moraru, C.I. Physical and chemical methods used to enhance the structure and mechanical properties of protein films: A review. J. Food Eng. 2013, 114, 292-302. [CrossRef]

14. Cao, T.L.; Song, K.B. Development of bioactive Bombacaceae gum films containing cinnamon leaf essential oil and their application in packaging of fresh salmon fillets. LWT-Food Sci. Technol. 2020, 131, 109647. [CrossRef]

15. Kowalczyk, D.; Gustaw, W.; Zieba, E.; Lisiecki, S.; Stadnik, J.; Baraniak, B. Microstructure and functional properties of sorbitolplasticized pea protein isolate emulsion films: Effect of lipid type and concentration. Food Hydrocoll. 2016, 60, 353-363. [CrossRef]

16. Nurul Syahida, S.; Ismail-Fitry, M.R.; Ainun, Z.M.A.; Nur Hanani, Z.A. Effects of palm wax on the physical, mechanical and water barrier properties of fish gelatin films for food packaging application. Food Packag. Shelf. 2020, 23, 100437. [CrossRef]

17. Cecchini, J.P.; Spotti, M.J.; Piagentini, A.M.; Milt, V.G.; Carrara, C.R. Development of edible films obtained from submicron emulsions based on whey protein concentrate, oil/beeswax and brea gum. Food Sci. Technol. Int. 2017, 23, 371-381. [CrossRef]

18. Zhang, Y.; Simpson, B.K.; Dumont, M.J. Effect of beeswax and carnauba wax addition on properties of gelatin films: A comparative study. Food Biosci. 2018, 26, 88-95. [CrossRef]

19. Yu, K.; Zhou, L.; Xu, J.; Jiang, F.; Zhong, Z.; Zou, L.; Liu, W. Carboxymethyl cellulose-based water barrier coating regulated postharvest quality and ROS metabolism of pakchoi (Brassica chinensis, L.). Postharvest Biol. Technol. 2022, 185, 111804. [CrossRef]

20. Wang, Z.; Sun, X.X.; Lian, Z.X.; Wang, X.X.; Zhou, J.; Ma, Z.S. The effects of ultrasonic/microwave assisted treatment on the properties of soy protein isolate/microcrystalline wheat-bran cellulose film. J. Food Eng. 2013, 114, 183-191. [CrossRef]

21. ASTM. Standard test methods for water vapor transmission of materials. In Annual Book of ASTM Standards; ASTM: Philadelphia, PA, USA, 2004.

22. Aline, O.E.S.I.; Stoll, L.; Belle, A.S.; Bellé, A.S.; Hertz, P.F.; Rios, A.O.; Rahier, H.; Flôres, S.H. Gelatin capsule residue-based films crosslinked with the natural agent genipin. Packag. Technol. Sci. 2020, 33, 15-26.

23. Beneventi, D.; Pugh, R.J.; Carré, B.; Gandini, A. Surface rheology and foaming properties of sodium oleate and $\mathrm{C}_{12}(\mathrm{EO})_{6}$ aqueous solutions. J. Colloid Interf. Sci. 2003, 268, 221-229. [CrossRef]

24. Wu, H.; Xiao, D.; Lu, J.; Jiao, C.; Li, S.; Lei, Y.; Liu, D.; Wang, J.; Zhang, Z.; Liu, Y.; et al. Effect of high-pressure homogenization on microstructure and properties of pomelo peel flour film-forming dispersions and their resultant films. Food Hydrocoll. 2020, 102, 105628. [CrossRef]

25. Zhang, R.; Wang, W.T.; Zhang, H.; Dai, Y.Y.; Dong, H.Z.; Hou, H.X. Effects of hydrophobic agents on the physicochemical properties of edible agar/maltodextrin films. Food Hydrocoll. 2019, 88, 283-290. [CrossRef]

26. Ma, X.; Yu, J.; He, K.; Wang, N. The effects of different plasticizers on the properties of thermoplastic starch as solid polymer electrolytes. Macromol. Mater. Eng. 2007, 292, 503-510. [CrossRef]

27. Deng, L.; Li, Y.; Zhang, A.; Zhang, H. Characterization and physical properties of electrospun gelatin nanofibrous films by incorporation of nano-hydroxyapatite. Food Hydrocoll. 2020, 103, 105640. [CrossRef]

28. Chawla, P.; Najda, A.; Bains, A.; Nurzyńska-Wierdak, R.; Kaushik, R.; Tosif, M.M. Potential of gum arabic functionalized iron hydroxide nanoparticles embedded cellulose paper for packaging of Paneer. Nanomaterials 2021, 11, 1308. [CrossRef] [PubMed] 
29. Tosif, M.M.; Najda, A.; Bains, A.; Zawiślak, G.; Maj, G.; Chawla, P. Starch-mucilage composite films: An inclusive on physicochemical and biological perspective. Polymers 2021, 13, 2588. [CrossRef]

30. Jamróz, E.; Juszczak, L.; Kucharek, M. Investigation of the physical properties, antioxidant and antimicrobial activity of ternary potato starch-furcellaran-gelatin films incorporated with lavender essential oil. Int. J. Biol. Macromol. 2018, 114, $1094-1101$. [CrossRef]

31. Khanzadi, M.; Jafari, S.M.; Mirzaei, H.; Chegini, F.K.; Maghsoudlou, Y.; Dehnad, D. Physical and mechanical properties in biodegradable films of whey protein concentrate-pullulan by application of beeswax. Carbohydr. Polym. 2015, 118, 24-29. [CrossRef]

32. Wicochea-Rodríguez, J.D.; Chalier, P.; Ruiz, T.; Gastaldi, E. Active food packaging based on biopolymers and aroma compounds: How to design and control the release. Front. Chem. 2019, 7, 398. [CrossRef]

33. Kim, D.; Park, I.; Seo, J.; Han, H.; Jang, W. Effects of the paraffin wax (PW) content on the thermal and permeation properties of the LDPE/PW composite films. J. Polym. Res. 2015, 22, 19. [CrossRef]

34. Gu, H.; Wang, C.; Gong, S.; Mei, Y.; Li, H.; Ma, W. Investigation on contact angle measurement methods and wettability transition of porous surfaces. Surf. Coat. Technol. 2016, 292, 72-77. [CrossRef]

35. Fabra, M.J.; Talens, P.; Chiralt, A. Tensile properties and water vapor permeability of sodium caseinate films containing oleic acid-beeswax mixtures. J. Food Eng. 2008, 85, 393-400. [CrossRef]

36. Morillon, V.; Debeaufort, F.; Blond, G.; Capelle, M.; Voilley, A. Factors affecting the moisture permeability of lipid-based edible films: A review. Crit. Rev. Food Sci. Nutr. 2002, 42, 67-89. [CrossRef] [PubMed]

37. Valizadeh, S.; Naseri, M.; Babaei, S.; Hosseini, S.M.H.; Imani, A. Development of bioactive composite films from chitosan and carboxymethyl cellulose using glutaraldehyde, cinnamon essential oil and oleic acid. Int. J. Biol. Macromol. 2019, 134, 604-612. [CrossRef] 